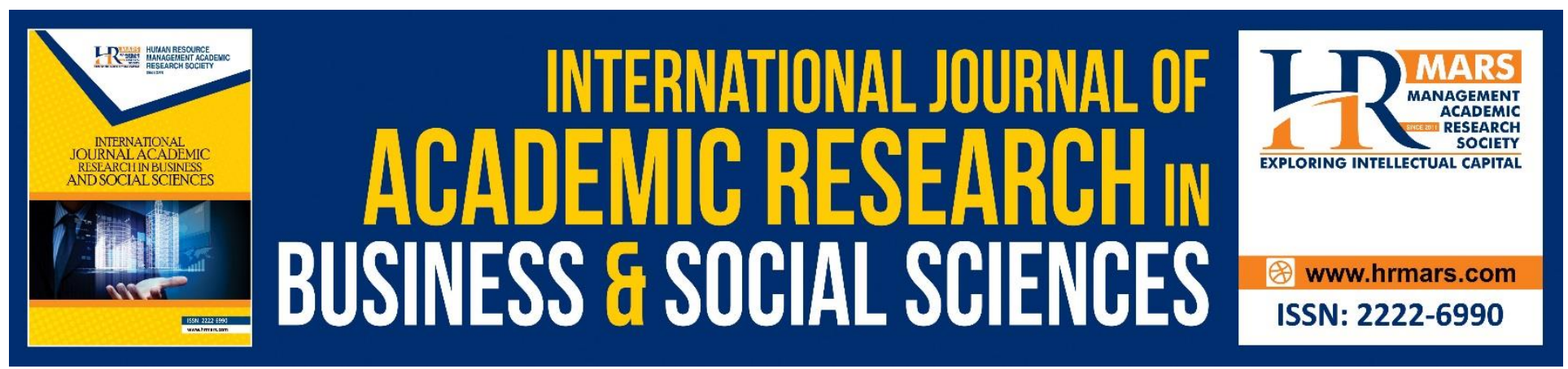

\title{
Compulsory Childhood Vaccination in Malaysia: Public Health versus Parental Autonomy
}

\author{
Khairun Nisaa Asari, Maheran Makhtar, Farhanin Abdullah Asuhaimi, \\ Nur Amani Pauzai
}

To Link this Article: http://dx.doi.org/10.6007/IJARBSS/v8-i12/5256

DOI: $10.6007 /$ IJARBSS/v8-i12/5256

Received: 02 Nov 2018, Revised: 23 Dec 2018, Accepted: 30 Dec 2018

Published Online: 16 Jan 2019

In-Text Citation: (Asari, Makhtar, Asuhaimi, \& Pauzai, 2018)

To Cite this Article: Asari, K. N., Makhtar, M., Asuhaimi, F. A., \& Pauzai, N. A. (2018). Compulsory Childhood Vaccination in Malaysia: Public Health versus Parental Autonomy. International Journal of Academic Research in Business and Social Sciences, 8(12), 1540-1548.

Copyright: @ 2018 The Author(s)

Published by Human Resource Management Academic Research Society (www.hrmars.com)

This article is published under the Creative Commons Attribution (CC BY 4.0) license. Anyone may reproduce, distribute, translate and create derivative works of this article (for both commercial and non-commercial purposes), subject to full attribution to the original publication and authors. The full terms of this license may be seen at: http://creativecommons.org/licences/by/4.0/legalcode

\section{Vol. 8, No. 12, 2018, Pg. 1540 - 1548}




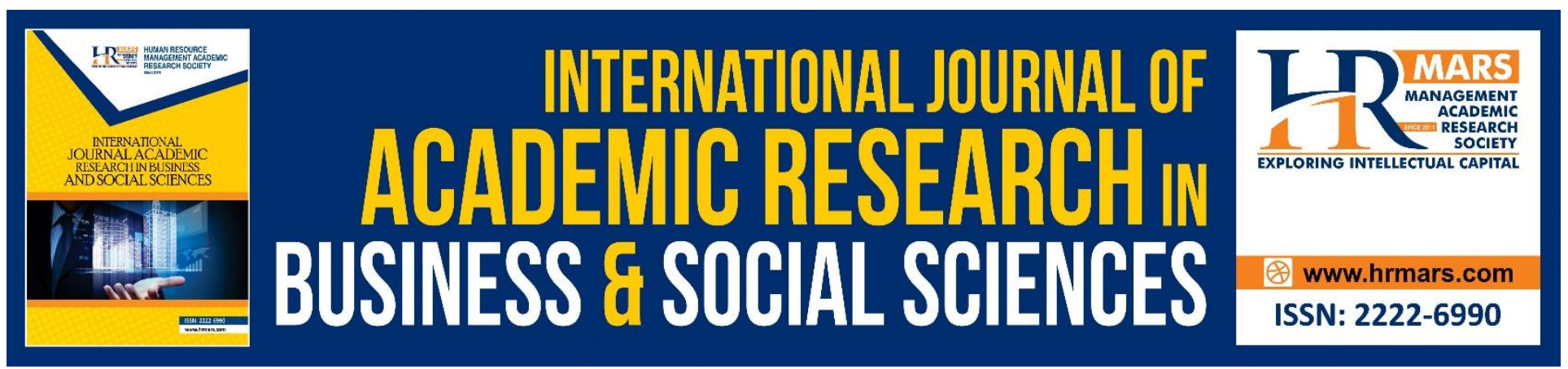

\title{
Compulsory Childhood Vaccination in Malaysia: Public Health versus Parental Autonomy
}

\author{
Khairun Nisaa Asari \\ Faculty of Law and International Relations, Universiti Sultan Zainal Abidin (UniSZA), Kampus Gong \\ Badak, 21300 Kuala Nerus, Terengganu, Malaysia. \\ Maheran Makhtar \\ Faculty of Law and International Relations, Universiti Sultan Zainal Abidin (UniSZA), Kampus Gong \\ Badak, 21300 Kuala Nerus, Terengganu, Malaysia
}

Farhanin Abdullah Asuhaimi

Faculty of Law and International Relations, Universiti Sultan Zainal Abidin (UniSZA), Kampus Gong Badak, 21300 Kuala Nerus, Terengganu, Malaysia

\section{Nur Amani Pauzai}

Faculty of Law and International Relations, Universiti Sultan Zainal Abidin (UniSZA), Kampus Gong Badak, 21300 Kuala Nerus, Terengganu, Malaysia

\begin{abstract}
Background: Following the death of two unvaccinated siblings, eleven months and two years old of diphtheria in June 2016, the Ministry of Health Malaysia is now emphasizing the need to enforce compulsory childhood vaccination in Malaysia. Vaccination is the main health intervention to reduce child mortality. Despite the success of vaccination, there has been an increase in the number of vaccine hesitancy, especially among parents. Research has identified many factors associated with parental vaccine refusal and hesitancy toward childhood vaccination, which varies from religious, medical as well as personal belief factors. This complicates matters as childhood vaccination involves a balance between parents' autonomy in deciding whether to vaccinate their children and the benefits to public health. Between parental autonomy in deciding to vaccinate their children and the benefits of vaccination to public health, which will prevail? Objective: This paper seeks to examine the ethical issues of enforcing compulsory vaccination for children in Malaysia. Results: if Malaysia were to come up with a legal framework of compulsory childhood vaccination, reference can be made to the legislated statutes in other countries, taking into account that some provisions such as exemptions to vaccination may be modified to suit it with Malaysian local circumstances and
\end{abstract}


INTERNATIONAL JOURNAL OF ACADEMIC RESEARCH IN BUSINESS AND SOCIAL SCIENCES

Vol. 8, No. 12, Dec, 2018, E-ISSN: 2222-6990 @ 2018 HRMARS

inhabitants. Conclusion: In improving health communication, aside from two way communications between parents and health officers, many other communication tools are also available. They include mass electronic media, digital media, print media, social mobilization and mobile technology.

\section{Introduction}

Unvaccinated individuals pose a public health threat to the society at large. The World Health Organization estimates that vaccines for diphtheria, pertussis, tetanus, and measles save between two and three million lives every year. Despite being cited as the most successful achievement in public health, certain groups still challenge this success by refusing vaccination for a variety of reasons including religious, scientific and political. The uncertainty towards vaccines leads to an increase in the number of people questioning and seeking alternatives for vaccines.

Vaccine hesitancy is an emerging term in vaccine decision-making. The SAGE Working Group on Vaccine Hesitancy defined vaccine hesitancy as a delay in acceptance or refusal of vaccination despite availability of vaccination services (Larson, et al, 2014). With the changes in modern times and technology, the attitude of parents started to change. Parents nowadays are better informed on the issue of vaccination, due to the fact that information on vaccines can be acquired easily online. The spread of anti-vaccine and vaccine-fear sentiments has become common through social networks, both online and in person also contributes to the exercise of parental autonomy in refusing to vaccinate their children.

Most of the studies analyzing the reasons for vaccine hesitancy or refusal among parents focused on parents' philosophical or ideological ideas. Vaccine hesitant parents often defend their position on the basis that what they believe is in the best interests of their children, or what they believe as good parenting'. Their reasons vary, however, with some believing that vaccines cause more harm than good, while some prefer natural immunity over unnatural vaccination. Meanwhile, others subscribe to the practice of free riding, that they will enjoy herd immunity without subjecting their child to the risk associated with vaccination (Diekema, 2005). Some refusals are due to the reason that there is no need for vaccination for eliminated illnesses seems justifiable, while some are quite absurd, for example the conspiracy theory that a government entity could be conducting intelligence gathering operations under the pretext of a vaccination program (Hendrix, et al, 2016). Other reasons for not vaccinating children include medical contraindications, insufficient communication with the medical staff, lack of knowledge or incorrect information among parents about vaccine-preventable diseases, low availability of and access to medical services, and low trust in medical authorities.

In a 2012 study in Malaysia, among the factors influencing compliance to vaccination depends on the parents, health officers as well as the environmental factors. The parents factor include lack of knowledge or inaccurate perception about the importance of vaccines and the seriousness of the diseases prevented by the vaccines, socioeconomic status, high birth order and big family size, single parent and families who live in temporary housing or who migrate between jobs. Meanwhile, the health officers factor include waiting time, motivation of health officers, suitability of the timing of immunization sessions, attitude of health officers, reaction to side effects and charges for the services. The environmental factors included logistic barriers, limited accessibility to health care due to poor roads or inadequate public transportation, preparedness of community for immunization sessions and information dissemination among the community (Azhar, et al, 2012). It can be 
concluded from the studies that parents demand the autonomous right to make decisions regarding their child's vaccinations, they perceive their refusal as characteristic of good parenting, and they are critical of and distrust the medical establishment. Other factors that affects vaccine acceptance/refusal include the gender of the baby, the mother's age, the mother's occupation, the mode of payment for the vaccine, the number of previous visits to the clinic by the parents, the number of counseling sessions given to the parents and the pre-counseling awareness or knowledge of rotavirus disease and rotavirus vaccine (Kannan, et al, 2010).

As part of the overall package of maternal and child health services in Malaysia, all children are provided with free immunization. It is available in all government health facilities where child health services are provided, both in rural and urban areas. Private sector, through private clinics and hospitals supplement the services. The Malaysia Ministry of Health provides childhood vaccination schedule which serves as a guideline for parents, however as of date there are no law making vaccine compulsory in Malaysia. The Parliament enacted the Prevention and Control of Infectious Diseases Act 1988 (PCIDA), a statute that relates to the spread of diseases which relates more to the prevention of importation of infectious disease and control of the spread of infectious disease in Malaysia.

\section{Results}

\section{PARENTAL AUTONOMY VERSUS PUBLIC HEALTH}

The parents approach to vaccination by making a decision based on parental autonomy places strong emphasis on the freedom, privacy and informed consent of parents in vaccine decision making. Current social conditions have encouraged greater patient autonomy in dealing with medical issues. In the case of childhood vaccination, patient autonomy comes in the form of parental autonomy as parents are the one who can make decisions with regard to their children medical needs, even if that decision is a refusal to accept medical treatment i.e. vaccination.

Will (2011) described the parents'refusal towards vaccination as their need of freedom to say "no" to the medical recommendation after considering the advantages and disadvantages as they analyzed the issue of vaccination. The choices they make seem rational to them, given the information they have. Beck and Giddens (1994) described this decision-making process as a reflexive thinking where in modern life, people make their own decisions by independent thinking, regardless of what the government says.

According to Aharon et al. (2017), most of the interviewed parents mentioned their demand for autonomy in making their own decisions about their body and health including vaccination administration. In their opinion, everyone should have the freedom to decide in this matter, and it is the parents'obligation and right to do as they see fit for their children. This includes choosing an alternative vaccination program, asking questions, and investigating the issue of vaccination.

Another contrasting concept in medical services, paternalism refers to the idea that sometimes action needs to be taken by the authorities to protect the health and welfare of the public, even though the action may be against their will. The action is by way of public health interventions, for example compulsory vaccination to prevent infectious disease which often infringe on the rights of individuals (parents). 
Health officers (doctors) are taught the principle of paternalism, which means actions done for the benefit of others. Thus when doctors impose on parents to vaccinate their children, their acts are carried out with the justification of doing good, i.e., protecting the welfare of the child and the public at large. This argument is often used to justify what would have been an intrusive public health intervention such as compulsory vaccination against particular contagious diseases, due to its overall benefits to society (Phua, 2013). Hence, we have programs such as compulsory vaccination schedules for children, with non-compliance being punished by exclusion of unvaccinated kids from public schools.

\section{Discussion}

\section{HOW FAR PARENTAL AUTONOMY OUTWEIGHS IMPORTANCE FOR PUBLIC HEALTH?}

In the United States Supreme Court case of Jacobson v Massachusetts in 2005, the US court upheld the right of states to pass compulsory vaccination laws. The decision later becomes one of the most important piece of public health jurisprudence. The Court's decision was based on the view that the freedom of the individual must sometimes be subordinated to the public health and welfare.

It was held that the liberty secured by the Constitution of the United States to every person within its jurisdiction does not import an absolute right in each person to be, at all times and in all circumstances, wholly freed from restraint. There are manifold restraints to which every person is necessarily subject for the common good. On any other basis organized society could not exist with safety to its members. Society based on the rule that each one is a law unto himself would soon be confronted with disorder and anarchy.

However since most of the dangerous infectious diseases such as smallpox and cholera receded from existence, the urgent need to justify coercive measures for ensuring public health was also reduced. As Parmet (1995) noted, endemic and chronic conditions are not a necessity which justified public health actions. They were simply part of the hazards of life. Thus, they no longer provoked enough fear to increase support for public health intervention.

It was agreed that individual rights of autonomy and public health are not always in harmony. Conflicts between individual rights and public health are unavoidable, and it is important to understand that sometimes restriction of limits of individual rights to protect public health may be necessary. Nevertheless, health officers generally opted for persuasive means rather than strict law enforcement to achieve high levels of voluntary acceptance. For example, only a number of states made diphtheria immunization compulsory during the two decades after its use became widespread (Colgrove and Bayer, 2005).

\section{PUBLIC HEALTH INTERVENTIONS FOR REDUCING PARENTAL VACCINE REFUSAL}

Restrictions on individual rights are justified for two reasons, for the benefit of the individual or the benefit of the community. In an emergency situation there may be a need to protect the health of an individual (a child) even though it means overriding parental autonomy. Many countries have compulsory vaccination requirements. These laws restrain parental autonomy in order to protect the public from infectious diseases since unvaccinated individuals pose great risk to the community. According to Salmon \& Omer (2006), when the state restrain individual (parents) freedom for the public good, the state assumes certain responsibilities and should address a number of issues. First, 
how great is the risk of non-vaccination? Moreover, a distinction should be made between vaccine refusal among adults versus parental vaccine refusal, as a parent does not have an absolute right to put a child at risk even if the parent is willing to accept such risk for him or herself. Third, policies that restrict individual rights by way of public health intervention anticipate the wider and long-term consequences of restricting individual autonomy. For example, a strict approach to vaccine policy may cause public criticism and leads to undermining of the sustainability of vaccine programs. Fourth, public authorities must put importance on the efficiency and safety of the vaccination program. For example, the authorities must create effective risk communication which provides clear and comprehensive description of the reasons for restricting individual rights.

It is suggested by Abdullah (2014) that the best interest of a child in vaccination is dependent upon the degree of vaccine coverage in a particular area. If more than 95 per cent of children in a particular country are vaccinated, the chance of an unvaccinated child to get infected by a vaccine-prevented disease is relatively low. Therefore, to vaccinate such a child is ethically wrong due to the risk of its side effects. In the case that the average is less than 80 per cent where there is no herd-immunity, vaccination is a valid choice as there is a widespread risks of vaccine-preventable diseases. In this case, the benefit of protection towards the vaccinated children outweighs the risk of suffering the side effects of vaccination.

\section{PROPOSAL FOR A LEGAL FRAMEWORK OF COMPULSORY CHILDHOOD VACCINATION}

Referring to what happened in the United States, the outbreak of a virus poses a real threat in terms of social and economic disruptions and even deaths. Currently in US, vaccination requirements are legislated at the state level. Every state grants exemptions from school-based vaccination programs for medical reasons and forty-eight states permit some form of religious opt-out. According to Mahmoud (2011), twenty states also permit philosophical exemptions based on personal beliefs or conscience.

In anticipation of a public health crisis, states have adopted new legislation or amended former emergency laws. The changes generally grant broad powers to state and health officials, including the power to order forced treatment and vaccination without specifying which exemptions, if any, will be granted to individuals in an emergency. This was criticized as possibly increasing the chances for state abuse of power.

State legislators also created opt-out provisions by way of medical, religious, and philosophical exemptions to vaccinations. However, these exemptions are accompanied with conditions such as placing restrictions on privileges, like the privilege of attending school. For example, during an outbreak of measles an unvaccinated child, exempt on a religious basis, would have to remain home from school until the outbreak subsided (Mahmoud, 2010).

Several countries with mandatory vaccination policies opt not to enforce them. Most countries also appear to agree that vaccination programs must allow for medical, religious and philosophical exemptions. In the United States, every state requires children to be vaccinated before attending school. In some states, parents can simply request exemptions, without having to provide a justification, while other states require a certified signature on a statement indicating that the parents are aware that they are putting their child at risk (Walkinshaw, 2011). 
Meanwhile, Australia offers financial incentives to boost compliance rates to vaccination. Parents receive nontaxable payments of $A \$ 129$ for each child who meets immunization requirements between 18 and 24 months of age, and again if the child meets requirements between four and five years of age. Even though vaccination is not compulsory in Australia, they have the Maternity Immunisation Allowance and Child Care Benefit which are parent incentive payments that are paid where a child is up to date with his/her vaccination or the parent has obtained an appropriate medical or philosophical exemption. According to Walkinshaw (2011), Australia does not require children to be immunized for school attendance but unvaccinated students are prohibited from attending classes in the event of disease outbreaks.

Other countries appear to have disease-specific compulsory vaccination programs. Belgium, for example, has a mandatory vaccination policy specifically for polio, which was enacted in 1967, that requires that all children to be vaccinated for the disease before they reach the age of 18 months. In Malaysia, where childhood vaccination is not compulsory under the law, we also do not have any specific emergency laws requiring compulsory vaccination in the case of public health crisis. The closest we have on statute on vaccination in Malaysia is Prevention and Control of Infectious Diseases Act 1988 (PCIDA), which relates more to the prevention of importation of infectious disease and control of the spread of infectious disease in Malaysia.

Thus, if Malaysia were to come up with a legal framework of compulsory childhood vaccination, reference can be made to the legislated statutes in other countries, taking into account that some provisions such as exemptions to vaccination may be modified to suit it with Malaysian local circumstances and inhabitants.

\section{Conclusion}

In conclusion, there is underlying tension between parental autonomy and protection of public health in the issue of vaccination. Despite the legal position, health officers may feel justified in promoting what they see to be the children's interests above their concern to respect parental wishes. At the same time, health officers might feel that respecting parents' choices is the most effective way to promote children's health. However, it may be reasonable to override a parental refusal if there is a great risk of harm to the child. The health officers statutory and moral duty is to ensure that the child receives vaccination as the child's life is at stake, no matter what the parental views.

It is suggested that health officers improve on their health communication. Health officers should consider that their professional duty requires them to listen to parents' views so that they are fully informed to help each child if the child's health falls below a certain standard, even if this involves acting against parental wishes. Goldstein, et al. (2015) stated there is evidence that communication, if carefully and strategically planned, can be an effective tool to influence the behaviours of populations on a number of health issues, including vaccine hesitancy. Example that communication can help people adopt positive health behaviours and create demand for preventive and curative services can be seen during the AIDS epidemic in 1985 when there was no treatment and the only tool for prevention was social and behaviour change.

In improving health communication, aside from two way communications between parents and health officers, many other communication tools are also available. They include mass electronic media, digital media, print media, social mobilization and mobile technology. The content of social 
INTERNATIONAL JOURNAL OF ACADEMIC RESEARCH IN BUSINESS AND SOCIAL SCIENCES

Vol. 8, No. 12, Dec, 2018, E-ISSN: 2222-6990 @ 2018 HRMARS

media needs to be better monitored with respect to attitudes to vaccines. This requires combined efforts from health officers, policymakers, and educationist in improving vaccine education and communication among the public.

\section{Corresponding Author}

Khairun Nisaa Asari. Faculty of Law and International Relations, Universiti Sultan Zainal Abidin (UniSZA), Kampus Gong Badak, 21300 Kuala Nerus, Terengganu, Malaysia.

Email: nisaa@unisza.edu.my.

\section{References}

1. Larson, H. J., Jarrett, C., Eckersberger, E., Smith, D. M.D. and Paterson, P., 2014. Understanding vaccine hesitancy around vaccines and vaccination from a global perspective: a systematic review of published literature, 2007-2012, Vaccine, 32: 2150-2159.

2. Diekema, D.S., 2005. Responding to parental refusals of immunization of children. Official Journal of the American Academy of Pediatrics, 115, 1428. Retrieved from http://pediatrics.aappublications.org/content/pediatrics/115/5/1428.full.pdf?ck=nck. Accessed March 2017

3. Hendrix, K. S., Sturm, L. A., Zimet, G. D. and Meslin, E. M., 2016. Ethics and childhood vaccination policy in the united states. American Journal of Public Health, 106(2), 273-278. http://doi.org/10.2105/AJPH.2015.302952.

4. Azhar, S. S., Nirmal, K., Safian, N., Rohaizat, H., Noor, A. A., and Rozita, H., 2012. Factors influencing childhood immunization defaulters in sabah, malaysia. The International Medical Journal of Malaysia, 11(1).

5. Kannan, K. P., Pathmanathan, G., and Salleh, N. M., 2010. Analysis of factors in response to rotavirus vaccination counselling in a private paediatric clinic. The Medical journal of Malaysia, 65: 127-132.

6. Will, J. F., 2011. A brief historical and theoretical perspective on patient autonomy and medical decision making: Part II: The autonomy model. Chest 139: 1491-1497. doi: 10.1378/chest.110516.

7. Beck. U. and Giddens, A., 1994. Reflexive modernization: Politics, tradition and aesthetics in the modern social order. California: Stanford University Press.

8. Aharon A.A., Nehama, H., Rishpon, S. and Bron-Epel, O., 2017. Autonomy and control among parents who do not comply with recommended pediatric vaccinations: a qualitative case study. Journal of Community and Public Health Nursing 3:152. doi:10.4172/2471-9846.1000152

9. Phua, K. L., 2013. Ethical dilemmas in protecting individual rights versus public protection in the case of infectious diseases. Infectious diseases, 6 (1).

10. Parmet, W. E., 1995. From Slaughter-House to Lochner: the rise and fall of the constitutionalization of public health. American Journal of Legal History, 40:476-505.

11. Colgrove, J., and Bayer, R., 2005. Manifold restraints: Liberty, public health, and the legacy of Jacobson v Massachusetts. American Journal of Public Health, 95(4), 571. 
12. Salmon, D. A., and Omer, S. B., 2006. Individual freedoms versus collective responsibility: immunization decision-making in the face of occasionally competing values. Emerging Themes in Epidemiology, 3, (13). http://doi.org/10.1186/1742-7622-3-13

13. Abdullah, A. B., 2014. Halal vaccine and the Ethical Dimension of vaccination programmes. Islam and Civilisational Renewal (ICR), 5(3).

14. Mahmoud, D.S., 2010. Balancing public health and individual choice: a proposal for a federal emergency vaccination law. Health Matrix, 20(1). 257.

15. Walkinshaw, E., 2011. Mandatory vaccinations: the international landscape. Canadian Medical Association Journal, 183(16).

16. Goldstein, S., MacDonald, N.E., Guirguis, S., and the SAGE Working Group on Vaccine Hesitancy, 2015. Health communication and vaccine hesitancy. Open Access Vaccine, 33: 4212-4214. 